\title{
Descrição morfológica dos ramos colaterais da aorta abdominal do tamanduá-mirim (Tamandua tetradactyla)
}

\author{
Breno Costa Macedo ${ }^{1}$ \\ Ana R. Lima ${ }^{1}$ \\ Luiza Corrêa Pereira ${ }^{2}$ \\ Érika Branco ${ }^{1 *}$ \\ ${ }^{1}$ Universidade Federal Rural da Amazônia \\ Avenida Presidente Tancredo Neves, 2501, CEP 66077-530, Belém - PA, Brasil \\ ${ }^{2}$ Área de Mina Bauxita, Vale Paragominas - PA, Brasil \\ *Autor para correspondência \\ ebranco.ufra@gmail.com
}

Submetido em 25/09/2012

Aceito para publicação em 07/01/2013

\section{Resumo}

Tamandua tetradactyla, Xenarthra, é uma espécie nativa da América do Sul que, devido aos poucos estudos acerca de sua biologia, ainda apresenta vários aspectos desconhecidos em sua morfologia. Tendo em vista a importância de dados morfológicos para diversos estudos, objetivou-se elucidar a ramificação da aorta abdominal dessa espécie para subsidiar a realização de futuros estudos. Para tal, foram utilizados quatro espécimes, sendo dois machos e duas fêmeas, todos jovens, provenientes da área de Mina Bauxita-Paragominas-PA, doados após morte por atropelamento ao Laboratório de Pesquisa Morfológica Animal (LaPMA) da Universidade Federal Rural da Amazônia (UFRA). O sistema arterial foi preenchido com látex contrastado e os animais fixados com solução de formol (10\%), sendo posteriormente dissecado, para evidenciar a aorta abdominal e seus ramos colaterais. Os ramos parietais eram constituídos por um par de artérias frênicas caudais, dois pares de artérias intercostais e três pares de artérias lombares. Dentre os ramos viscerais, destacaram-se: artéria celíaca; artéria mesentérica cranial; artérias adrenais; artérias renais; artéria mesentérica caudal; e artérias ilíacas externas, internas e sacral mediana, que se formaram a partir da porção final da aorta abdominal. As artérias testiculares e ováricas tiveram origem nas artérias renais, divergindo daquilo descrito em diversas espécies.

Palavras-chave: Anatomia comparada; Aorta abdominal; Estudo vascular; Tamandua tetradactyla

\section{Abstract}

Morphological description of collateral branches from the abdominal aorta of lesser anteater (Tamandua tetradactyla). Tamandua tetradactyla, Xenarthra, is a native species from South America which, due to the few number of studies on its biology, still has many unknown aspects in its morphology. Taking into account the importance of morphological data for various studies, this paper aimed to elucidate the branching of the abdominal aorta in this species to foster the development of further studies. To do this, 4 specimens were used, 2 male and 2 female, all young, from the Bauxite Mine - Paragominas, Para, Brazil, donated after death due to running over to the Animal Morphology Research Laboratory (LaPMA) of Universidade Federal 
Rural da Amazonia (UFRA). The arterial system was filled with contrasted latex and the animals were fixed in a formaldehyde solution (10\%), and then dissected, in order to evidence the abdominal aorta and its collateral branches. The parietal branches consisted of 1 pair of caudal phrenic arteries, 2 pairs of intercostal arteries, and 3 pairs of lumbar arteries. Among the visceral branches, stood out: celiac artery; cranial mesenteric artery; adrenal arteries; renal arteries; caudal mesenteric artery; and external, internal, and median sacral iliac arteries, formed from the final portion of the abdominal aorta. Testicular and ovarian arteries originated from the renal arteries, differing from that described in various species.

Key words: Abdominal aorta; Comparative anatomy; Tamandua tetradactyla; Vascular study

\section{Introdução}

O Tamandua tetradactyla é um Xenarthra nativo da America do Sul, conhecido popularmente como tamanduá-mirim ou tamanduá-de-colete, devido sua pelagem característica. Geograficamente, esta espécie se distribui do leste dos Andes, por toda Venezuela até o norte da Argentina. No Brasil se difunde por todos os biomas: Caatinga, Cerrado, Amazônia, Mata Atlântica, Campos Sulinos e Pantanal (REIS et al., 2006).

De hábitos solitários em natureza (vistos em casais apenas no período reprodutivo), são predominantemente noturnos, insetívoros com alimentação constituída basicamente de formigas, abelhas e térmitas. Estes animais são adaptados a estratos arbóreos, medindo aproximadamente 470 a $770 \mathrm{~mm}$, de corpo compacto com focinho longo e cônico, somado a uma cauda preênsil medindo entre 402 e $672 \mathrm{~mm}$ (CUBAS et al., 2007).

A ordem Xenarthra, anteriormente nominada Edentata, apresenta algumas peculiaridades anatômicas dentre as quais se destacam as articulações adicionais entre as vértebras lombares, exclusiva desta Ordem, que permitem aos membros deste grupo assumir uma postura ereta tendo como base os membros pélvicos e a cauda formando assim um tripé, dentre outros aspectos morfofisiológicos únicos já observados nesta Ordem, a relatos da presença de uma veia cava caudal par, genitália externa indiferenciada, baixo metabolismo e temperatura corpórea, a qual varia entre $32,7^{\circ} \mathrm{C}$ e $35,5^{\circ} \mathrm{C}(\mathrm{McNAB}$, 1985; REIS et al., 2006). No entanto podemos afirmar que pouco ainda se sabe sobre a morfologia básica nos membros desta Ordem.

Tendo em vista a importância da anatomia sistêmica para a compreensão fisiológica destes animais e das vastas possibilidades de estudos no âmbito da anatomia comparada, este trabalho ambicionou descrever sistematicamente a aorta abdominal e seus ramos colaterais, responsáveis pela vascularização arterial da cavidade abdominal do Tamandua tetradactyla.

\section{Material e Métodos}

Foram utilizados quatro espécimes de Tamandua tetradactyla sendo dois machos e duas fêmeas jovens, provenientes da área Paragominas-PA, sob autorização SEMA-PA № 455/2009 e 522/2009, doados pósóbito por atropelamento ao Laboratório de Pesquisa Morfológica Animal (LaPMA) da Universidade Federal Rural da Amazônia (UFRA).

Inicialmente a pele e os músculos ventro-laterais do tórax foram rebatidos, seguido de remoção parcial do esterno e de algumas costelas no antímero esquerdo, permitindo a visualização e canulação do arco aórtico seguindo de preenchimento com látex Neoprene 650 , corado com pigmento vermelho $\left(\mathrm{Xadrez}^{\circledR}\right)$ e adicionado contraste baritado (Barioge ${ }^{\circledR}$ - Cristalia), na proporção de $1: 1$, para visualização dos vasos através de radiografia. Em seguida, os espécimes foram fixados, por meio da infusão intramuscular e intracavitária, de solução aquosa de formaldeído a $10 \%$, com posterior submersão dos cadáveres na mesma solução fixadora, por um período mínimo de sete dias.

Os animais foram radiografados com equipamento apropriado (Intecal ${ }^{\circledR}$, modelo CR-7), na potência de $100 \mathrm{kV}$ e $100 \mathrm{~mA}$, utilizando-se filmes de $24 \times 30 \mathrm{~cm}$ $\left(\mathrm{AGFA}^{\circledR}\right)$, mantendo distância foco filme de $90 \mathrm{~cm}$, com exposição de $50 \mathrm{kV}, 100 \mathrm{~mA}$ e tempo $0,2 \mathrm{seg}$ e em seguida, as artérias abdominais foram dissecadas 
a partir de incisão na cavidade abdominal ao nível da linha média, desde a cartilagem xifóide até próximo a genitália externa.

Estrutura e posicionamento do diafragma, arcabouço vertebral e aspectos gerais da delimitação da cavidade abdominal foram observados com posterior deslocamento lateral das vísceras iniciando a evidencialização da aorta abdominal e de seus ramos colaterais.

Toda nomenclatura adotada foi baseada no proposto pelo International Committee on Veterinary Gross Anatomical Nomenclature (2012).

\section{Resultados}

Todos os animais estudados apresentaram 17 vértebras torácicas, três vértebras lombares e cinco vértebras sacrais, o que contribui para a forma e delimitação peculiar da cavidade abdominal, evidenciada por um número reduzido de vértebras lombares que estruturaram essa região, assim como por um diafragma que se estendeu dorsalmente, delimitando a maior parte da cavidade e inserindo-se também no plano dorsal, entre as duas últimas costelas (T16 e T17) ao nível dos rins que se apresentaram de forma quase simétrica entre si, sendo o direito discretamente mais cranial. A porção lombar do diafragma apresentou-se constituída por dois pilares que se inseriram simetricamente através de ligamento na segunda vértebra lombar. Ventralmente o diafragma interpôs-se a altura da cartilagem xifóide entre a $11^{\mathrm{a}} \mathrm{e}$ $12^{\mathrm{a}}$ costelas e cranialmente revelou formato de cúpula pouco acentuada (Figuras 1A e 1B). Essa conformação particular evidenciou um caráter diferenciado a cavidade abdominal, de modo que a aorta abdominal atravessou o hiato aórtico em nível de T16. A aorta abdominal dispôs-se medianamente aderida ao teto da cavidade abdominal ladeada pelas duas veias cavas caudais (Figuras 2A e 2B).

Os ramos parietais foram constituídos por um par de artérias frênicas caudais, dois pares de artérias intercostais e três pares de artérias lombares (Figura 2). Artérias intercostais e lombares originaram-se medianamente junto ao corpo das respectivas vértebras,

FIGURA 1: (A): Esquema do arcabouço vertebral no Tamandua tetradactyla discriminando as regiões: cervical, torácica, lombar e sacral. (B): Imagem Radiográfica de Tamandua tetradactyla, macho, em decúbito dorsal, pós infusão de látex contrastado. Observar: 1 - aorta abdominal; 2 - a. hepática; 3 - a. esplênica; 4 - a. mesentérica cranial; 5 - Aa. renais; 6 - a. ilíaca externa; 7 - a. ilíaca interna; 8 - a. sacral mediana.
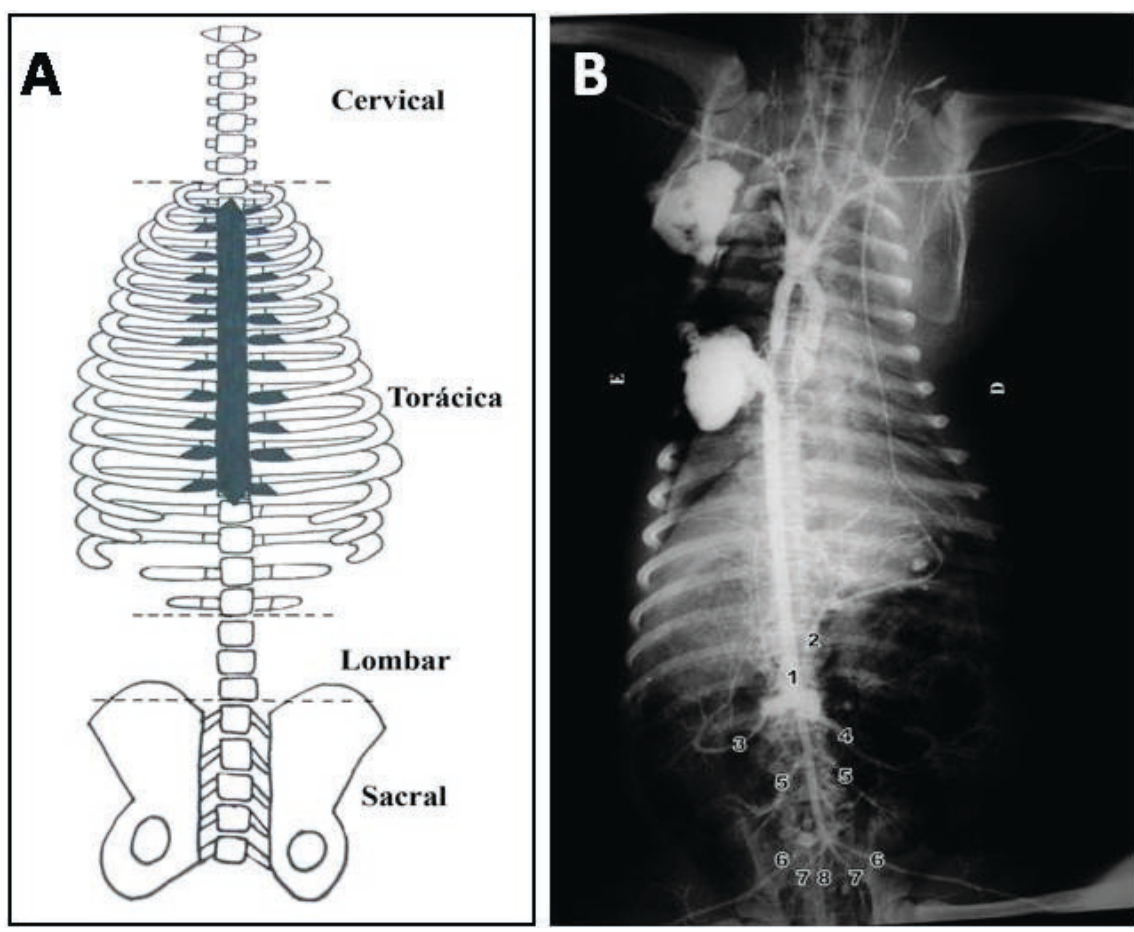
porém, com origem dorsolateral, referenciando topograficamente a origem dos ramos viscerais (Figura 2). De forma geral, o primeiro ramo visceral emitido pela aorta abdominal foi a artéria celíaca, que originou-se ventral e imediatamente após o diafragma, ao nível do primeiro par de artérias intercostais e se trifurcou originando a artéria gástrica esquerda, artéria hepática e artéria esplênica, porém, isto só foi observado nos machos e em uma das fêmeas (Figura 2A). Na outra fêmea estudada a artéria celíaca se bifurcou originando as artérias gástrica esquerda e esplênica sendo a artéria hepática um ramo colateral da artéria mesentérica cranial, que neste animal apresentou origem ventral justaposta ao tronco celíaco (Figura 2B). Nos demais animais a artéria mesentérica cranial teve origem ventral em nível do segundo par de artérias intercostais acompanhando o mesotélio e formando ramificações menores em todos os animais (Figuras 1B e 2).
A artéria gástrica esquerda vascularizou a região fúndica do estômago, enquanto a artéria esplênica irrigou o baço, pâncreas e regiões fúndica e cárdica do estômago. A artéria hepática irrigou a região pilórica do estômago, fígado, duodeno e também parte do pâncreas.

As artérias adrenais e frênicas caudais esquerdas emergiram da aorta abdominal de forma constante em um ponto comum ventrolateralmente a origem da artéria celíaca em T16 em três animais e em T17 no outro espécime. As artérias frênica caudal e adrenal direita apresentaram maior variação quanto à sua origem, emergindo de um tronco comum em apenas dois animais, sendo em um destes como ramo colateral da aorta abdominal em nível de T16 e no outro como ramo colateral da artéria mesentérica cranial. Nos demais animais, estas artérias emergiram separadamente da região de inserção da artéria renal direita (Figuras 2A e 2B).

FIGURA 2: Aorta abdominal e seus ramos colaterais em 2 espécimes de Tamandua tetradactyla, macho (A) e fêmea (B). 1 - aorta abdominal; 2 - a. celíaca; 3 - a. hepática (notar que na fêmea (B) a artéria. hepática emerge da artéria mesentérica cranial); 4 - a. gástrica esquerda; 5 - a. esplênica; 6 - Aa. frênicas caudais esquerda e direita; 7 - a. adrenal; 8 - a. mesentérica cranial; 9 - Aa. renais; 10 - ramos adrenais caudais; 11 - a. testicular (A) e ovárica (B); 12 - a. mesentérica caudal; 13 - a. ilíaca externa; 14 - a. ilíaca interna; 15 - a. sacral mediana (observar que na fêmea (B), essas três artérias partem de um tronco comum*); 16 - segunda artéria intercostal esquerda (encoberta pela a. renal em B); 17 - primeira artéria lombar esquerda (encoberta pela a. renal em A); 18 - segunda artéria lombar esquerda; 19 - terceira artéria lombar esquerda; Em (B) é possível notar a artéria frênica acessória ${ }^{+}$.

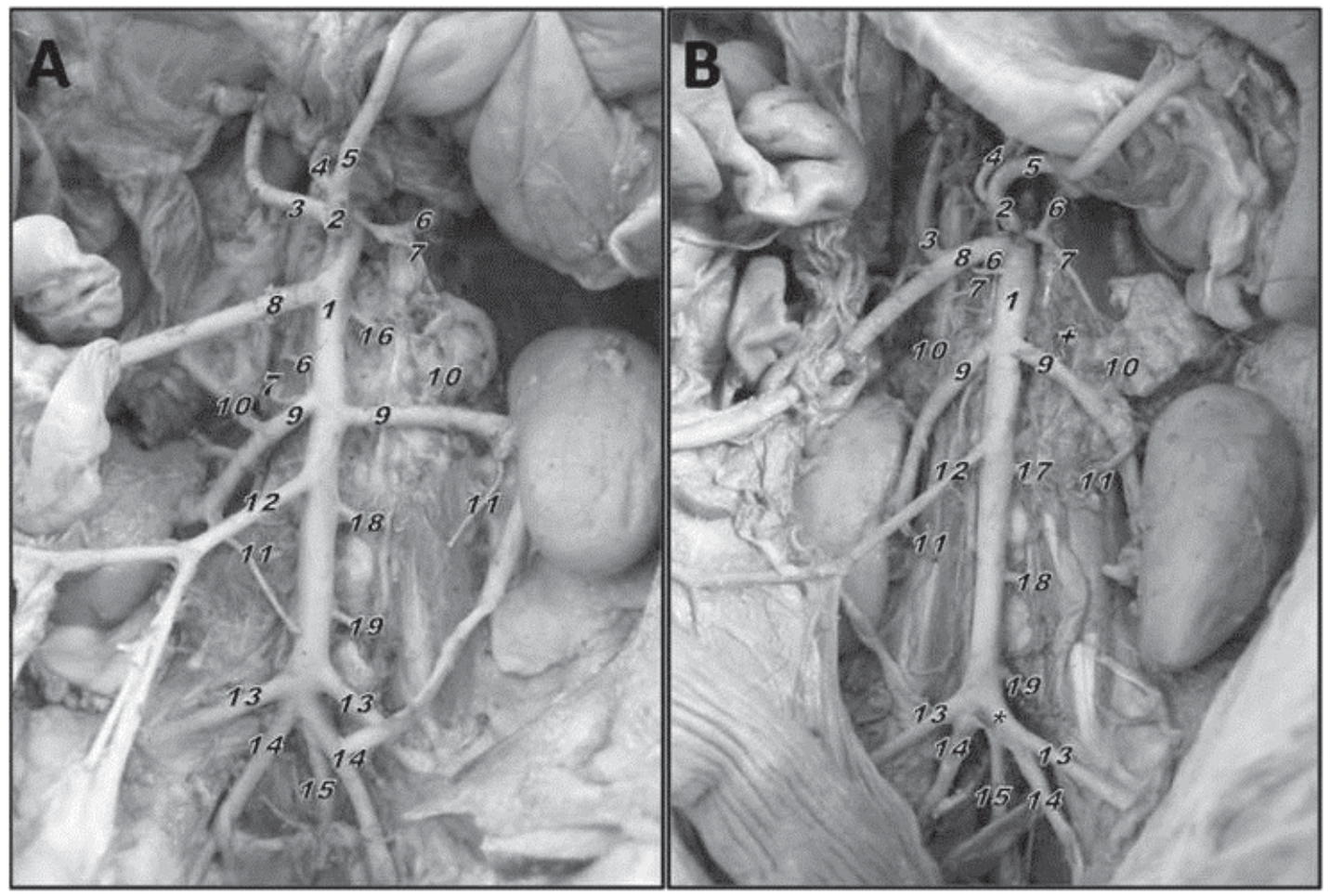


As artérias frênicas caudais, direita e esquerda irrigaram o diafragma em seus respectivos antímeros, enquanto que as artérias adrenais foram responsáveis pela parcial nutrição das glândulas adrenais sendo estas também assistidas por uma série de ramos originados do segundo terço das artérias renais constituindo os ramos adrenais caudais (Figura 2A e 2B).

Nas fêmeas, as artérias renais se originaram ventrolateralmente na altura do segundo par de artérias torácicas, em nível de T17 (Figura 2B), já nos machos, estas originaram-se na altura do primeiro par de vértebras lombares, em nível de L1 (Figuras 1B e 2A). A emissão da artéria renal direita se deu cranialmente acompanhando a topografia do órgão. As artérias renais emitiram ainda um ou mais ramos colaterais para o pólo renal cranial em $50 \%$ dos rins, tendo estes ramos origem anterior às artérias gonadais (Figuras 2A e 2B). Dois animais apresentaram ainda ramos colaterais da artéria renal esquerda irrigando o diafragma constituindo uma artéria frênica acessória (Figura 2B).

Quanto à artéria mesentérica caudal, esta apresentou origem ventral na altura do segundo par de artérias lombares nos machos e em nível do primeiro par nas fêmeas (Figuras 2A e 2B).

As artérias gonadais se originaram da porção terminal das artérias renais sendo as artérias testiculares mais longas devido ao posicionamento mediano dos testículos na porção transicional entre a cavidade abdominal e a cavidade pélvica, enquanto que os ovários dispuseram-se craniolateralmente, exclusivamente na cavidade abdominal (Figuras 2A e 2B).

A aorta abdominal, em sua porção terminal, emitiu lateralmente, em três animais, dois machos e uma fêmea, as artérias ilíacas externas, e imediatamente após bifurcou-se originando as artérias ilíacas internas, sendo a artéria sacral mediana um ramo oriundo da artéria ilíaca interna esquerda (Figuras 1B e 2A).

$\mathrm{Na}$ outra fêmea estudada observou-se que a ilíaca interna esquerda assim como a sacral mediana e a ilíaca externa esquerda originaram-se de um tronco comum emitido da porção final da aorta abdominal enquanto que no antímero direito estas tiveram origem individual conforme descrito nos demais animais (Figura 2B).

\section{Discussão}

A coluna vertebral estende-se do crânio até a ponta da caudal estruturando-se e seguindo um padrão comum característico de suas diversas regiões, no entanto a constituição numérica destas regiões apresenta significantes variações conforme espécies e em menor grau oscilam entre indivíduos. A região cervical é constituída por sete vértebras na maioria dos mamíferos tendo início na inserção do crânio e se estendendo até a inserção da primeira costela. A região torácica apresenta notável variação quanto ao número de vértebras, acompanhando as peculiaridades das espécies no qual, em cães, gatos, bovinos, caprinos e ovinos esta é geralmente constituída por 13 unidades vertebrais de acordo com sua cavidade torácica menos volumosa. Em suínos, tal variação pode oscilar entre 14 e 15 vértebras, nos equinos, cuja cavidade torácica e particularmente volumosa, encontramos 18 vértebras (DYCE et al., 2004). A semelhança do descrito em equinos, o tamanduá-mirim possui tórax alongado, porém, o diafragma deste animal toma um posicionamento mais oblíquo que o descrito na maioria das espécies domésticas, situação esta que somada ao corpo compacto, oferece ao Tamandua tetradactyla uma delimitação particular da cavidade torácica e abdominal.

No que tange a outras espécies de Xenartras, Buchholtz e Stepien (2009) descreveram uma ampla variação no número de vértebras em preguiças dos gêneros Bradypus e Choloepus, atribuindo tal diversidade a uma reestruturação do esqueleto axial a partir de um ancestral comum, que apresenta notável semelhança com o observado no espécime alvo de nosso estudo. Os autores revelam que tal ancestral possuía sete vértebras cervicais, 14 torácicas, três lombares e cinco sacrais, divergindo do presente trabalho apenas quanto ao número de vértebras torácicas, uma vez que se contabilizou 17 no tamanduámirim

O tatu-peba, Euphractus sexcinctus, também Xenartha, apresenta sete vértebras cervicais, apenas dez vértebras torácicas, cinco vértebras lombares e o sacro diferenciado fundido ao íleo a semelhança do descrito em aves (ALBERTO et al., 2010). 
Do ponto de vista vascular, a artéria celíaca, conforme descrita na maioria dos animais domésticos e selvagens se apresentou como primeiro ramo, impar e visceral se trifurcando em $75 \%$ dos casos nas artérias gástrica esquerda, hepática e esplênica como descrita em equinos, carnívoros, suínos, bovinos, caprinos (DYCE et al., 2004), cutias (CARVALHO et al., 1994), ratãodo-banhado (MACHADO et al., 2002b), e na nutria (CULAU et al., 2008b).

A bifurcação da artéria celíaca formando os troncos hepatoesplênico ou gastroesplênico ou gastroepático não é rara e já foi descrita em diversas espécies como, na cutia (CARVALHO et al., 1994), no suíno e no cateto (CAVALCANTE FILHO et al., 1998). Essa condição não foi verificada nos espécimes estudados, no entanto, não há registros na literatura descrevendo a artéria hepática como originária da artéria mesentérica cranial conforme relatamos neste estudo.

A literatura é escassa no que concerne à irrigação arterial em Xenartra, todavia, no que se refere à ramificação da artéria celíaca, na preguiça comum (Bradypus variegatus), esta artéria é descrita como originando de forma variável, seus ramos esplênicos, gástrico, duodenal, pancreático e abdominal (AMORIM et al., 2003b). No tamanduá-bandeira a artéria celíaca é descrita originando-se individualmente e se trifurcando (BONATELLI et al., 2003) conforme descrito no presente trabalho.

As artérias mesentéricas são os vasos responsáveis pelo suprimento sanguíneo do intestino delgado e grosso. Nos animais domésticos, a artéria mesentérica cranial origina-se caudalmente à artéria celíaca, com a qual forma em alguns casos, um tronco comum. A artéria mesentérica caudal é um vaso ímpar que se origina próximo à divisão terminal da aorta, dividindose após um curto trajeto (NICKEL et al., 1981). Apesar de não termos encontrado em nossos estudos a existência de tronco comum entre as artérias celíaca e mesentérica cranial, tal fato é amplamente relatado em diversas espécies, como em ovinos (LANGENFELD; PASTEA, 1977), caprinos (FERREIRA et al., 2001), felinos (PEDUTI NETO; BORELLI, 1970) e caninos (SCHMIDT; SCHOENAU, 2007). Em bubalinos o tronco comum tem origem na aorta torácica e adentra a cavidade abdominal via hiato aórtico (MACHADO et al., 2000).

Em algumas espécies de Xenartras há relato da presença de um tronco comum entre a artéria celíaca e a artéria mesentérica cranial, como é o caso da preguiça comum (Bradypus variegatus), assim como da típica origem individual das artérias celíaca e mesentérica cranial. De forma diferenciada, consta ainda na literatura, a formação de uma artéria mesentérica comum (AMORIM et al., 2003a).

De acordo com Souza et al. (2010), no tamanduábandeira os intestinos delgado e grosso fixam-se na parede dorsal da cavidade abdominal por uma grande prega peritoneal em uma raíz mesotélica comum, e conformação similar foi encontrada no Tamandua tetradactyla. Acrescenta-se, porém, o fato de que todos os ramos colaterais impares desta espécie transitaram inicialmente nesta raíz mesotélica.

As artérias mesentéricas cranial e caudal são paralelas e com trajeto determinado pela conformação peculiar de seu mesotélio conforme relatado no tamanduá-bandeira. Esta conformação está associada a um padrão primitivo de intestino atribuído aos Xenarthras (SOUZA et al., 2010).

A origem da artéria mesentérica cranial justaposta, descrita em um espécime fêmea deste trabalho é comumente encontrada em ruminantes, nos quais as artérias mesentérica cranial e a celíaca não se originam de tronco comum (GETTY, 1986) assim como na nutria (CULAU et al., 2008b).

A artéria frênica caudal e a artéria frênica abdominal têm origem comum nos cães (EVANS; DE LAHUNTA, 1999) e na nutria (CULAU et al., 2008a), porém, iniciando do tronco celíaco em alguns ruminantes (GETTY, 1986) e nos suínos (GONÇALEZ et al., 2003). São encontrados relatos da irrigação da glândula adrenal por ramos originários da artéria frênica caudal em diversas espécies como suínos (CARNEIRO et al., 2001), cães (EVANS; DE LAHUNTA, 1999), cutia (CARVALHO et al., 1999) e na nutria (CULAU et al., 2008b), mas sempre de forma e frequência variável, o mesmo se verifica com a irrigação da glândula adrenal por ramos da artéria renal como também é relatado em 
suínos (CARNEIRO et al., 2001), cutia (CARVALHO et al., 1994; NEVES et al., 2007) e nutria (MACHADO et al., 2002a), no entanto, salientamos a irrigação da adrenal por uma artéria única que se originou junto à artéria frênica caudal em $75 \%$ dos casos e individualmente nos demais $25 \%$. Foi observado um número variável de ramos adrenais caudais originados nas artérias renais em todos os animais de nosso estudo.

As artérias renais do Tamandua tetradactyla seguiram o padrão descrito nos animais domésticos nos quais a artéria renal direita originou-se um pouco mais cranial em relação à esquerda acompanhando a posição relativamente mais cranial do rim direito (NICKEL et al., 1981).

As artérias gonadais têm origem variável amplamente relatada. Na maioria dos animais domésticos, dentre estes, cães, suínos, equinos e pequenos ruminantes é descrita como ramo da aorta abdominal, em bovinos a artéria testicular segue este padrão, no entanto a artéria ovárica é descrita como ramo colateral da artéria ilíaca externa (DYCE et al., 2004).

Na nutria, as artérias ilíacas externas emitem como ramos colaterais as artérias umbilicais que originam as artérias uterinas e testiculares responsáveis pela irrigação das gônadas (CULAU et al., 2008b). Atipicamente, no tamanduá-mirim as artérias gonadais foram emitidas como ramo colateral das artérias renais, condição também descrita no tamanduá-bandeira (BONATELLI et al., 2003) e no Podocnemis unifilis (HIRANO et al., 2009) havendo ainda relatos de casos em equinos como condição atípica (GETTY, 1986).

As artérias ilíacas têm origem diferenciada nas espécies podendo as ilíacas externas e internas se originarem da aorta abdominal individualmente, como é caso dos equinos, bovinos, suínos (GETTY, 1986) e dos cães (EVANS; DE LAHUNTA, 1999) ou ainda as artérias ilíacas podem surgir de um tronco comum, conforme descrito em caprinos (GETTY, 1986), no gambá (CULAU et al., 2002) e na nutria (CULAU et al., 2008a).

Quanto à artéria sacral mediana, esta é a continuação da aorta abdominal, posterior a emissão das ilíacas internas no cão, suínos, bovinos (DYCE et al., 2004) e tamanduá-bandeira (BONATELLI et al., 2003). Em caprinos (GETTY, 1986) e na nutria (CULAU et al., 2008a) é descrita como um vaso de origem dorsal.

No Tamandua tetradactyla devido ao corpo compacto, as artérias ilíacas tiveram origem muito próximas e lateralizadas, ao contrário do descrito por Getty (1986) em animas com abdômen mais volumoso como bovinos e suínos, nos quais a artéria ilíaca externa tem origem ventral. A artéria sacral mediana em contraste com o descrito nos animais domésticos (DYCE et al., 2004) e na nutria(CULAU et al. 2008a), teve origem constante como ramo colateral da artéria ilíaca interna esquerda.

O sistema arterial e a delimitação da cavidade abdominal do $T$. tetradactyla demonstraram-se diferentes de todas as espécies encontradas na literatura, seja pela peculiar distribuição das vértebras (17 torácicas e três lombares), ou pelo diafragma atípico acentuadamente oblíquo se estendendo dorsalmente. A aorta abdominal apresentou como ramos colaterais viscerais às artérias ilíacas, renais, adrenais, mesentéricas e ao tronco celíaco. Como ramos parietais às artérias frênicas caudais, dois pares de artérias intercostais e três pares de artérias lombares.

\section{Referências}

ALBERTO, M. L. V.; OLIVEIRA, C. M.; RODRIGUES, M. N.; OliveirA, A. B.; MiglinO, M. A.; AMBROSIO C. E. Funções ósseas do esqueleto de tatu (Euphractus sexcinctus). Acta Veterinaria Brasilica, Mossoró, v. 4, p. 86-91, 2010.

AMORIM, M. J. A. A. L.; AMORIM JÚNIOR, A. A.; ARAÚJO, F. P.; PIMENTEL, D. S.; SILVA, D. R. Arranjos anatômicos da artéria mesentérica cranial e caudal no bicho-preguiça (Bradypus variegatus SHINZ, 1825). International Journal of Morphology, Temuco, v. 21, n. 1, p. 18, 2003a.

AMORIM, M. J. A. A. L.; AMORIM JÚNIOR, A. A.; ARAÚJO, F. P.; PIMENTEL, D. S.; SILVA, D. R. Arranjos anatômicos da artéria celíaca e seus ramos no bicho-preguiça (Bradypus variegatus SHINZ, 1825). International Journal of Morphology, Temuco, v. 21 , n. 1 , p. $17-18,2003$ b

BONATELLI, M.; SANTOS, T. C.; PAPA, P.; AZARIAS, R. E. G. R.; MIGLINO, M. A.; PASSIPIÉRI, M.; MARTINS, D. S.; AMBRÓSIO, C. E.; OLIVEIRA, M. F. Descrição anatômica dos ramos da aorta abdominal do tamanduá bandeira (Myrmecophaga tridactyla). International Journal of Morphology, Temuco, v. 21, n. 1, p. 35-36, 2003.

BUCHHOLTZ, E. A.; STEPIEN, C. C. Anatomical transformation in mammals: developmental origin of aberrant cervical anatomy in 
tree sloths. Evolution \& Development, Bloomington, v. 11, n. 1, p. 69-79, 2009.

CARVAlhO, M. A. M.; MiGLinO, M. A.; DiDiO, L. J. A. Ramificaçäo e distribuiçäo da artéria celíaca na cutia (Dasyprocta aguti)/Branching and distribution of the coeliac artery in "cutias" (Dasyprocta aguti, Rodentia). Brazilian Journal of Veterinary Research and Animal Science, São Paulo, v. 31, n. 3-4, p. 191197, 1994

CARVAlho, M. A. M.; MIGLinO, M. A.; DiDIO, L. J. A.; MELO, A. P. F. Artérias mesentéricas cranial e caudal em cutias (Dasyprocta aguti). Veterinária Notícias, Uberlândia, v. 2, p. 1724, 1999.

CAVALCANTE FILHO, M. F.; MIGLINO, M. A.; MACHADO G. V.; BEVILACQUA E.; NEVES W. C. Estudo comparativo sobre o suprimento arterial do estômago do queixada (Tayassu pecari) e do cateto (Tayassu tajacu) [Linnaeus, 1789]. Brazilian Journal of Veterinary Research and Animal Science, São Paulo, v. 35, n. 1, p. 20-24, 1998.

CUBAS, Z. S.; SILVA, J. C. R.; CATÃO-DIAS, J. L. Tratado de animais selvagens. São Paulo: Roca, 2007. 1376 p.

CULAU, P. O. V.; LINDEMANN, T.; RECKZIEGEL, S. H. Ramos terminais da artéria aorta abdominal no gambá (Didelphis albiventris). In: CONGRESSO BRASILEIRO DE ANATOMIA, XX, 2002, Maceió. Resumos... Maceió: SBA, 2002. p. 91. Versão eletrônica.

CUlAU, P. O. V.; AZAMBUJA, R. C. A.; CAMPOS, R. Ramos colaterais parietais e terminais da aorta abdominal em Myocastor coypus (nutria). Ciência Rural, Santa Maria, v. 38, n. 4, p. 9971002, 2008a.

CULAU, P. O. V.; AZAMBUJA, R. C. A.; CAMPOS, R. Ramos colaterais viscerais da artéria aorta abdominal em Myocastor coypus (nutria). Acta Scientiae Veterinariae, Porto Alegre, v. 36, n. 3, p. 241-247, 2008b.

DYCE, K. M.; SACK, W. O.; WENSING, C. J. G. Tratado de Anatomia Veterinária. 3. ed. Rio de Janeiro: Elsevier, 2004. 813 p.

EVANS, H. E.; DE LAHUNTA, A. Guia para dissecção do cão. 3 ed. Rio de Janeiro: Guanabara Koogan, 1999. 199 p.

FERREIRA, F. A.; MiglinO, M. A.; SILVA, F. O. C.; CARVALHO, F. S. R.; SANTOS, T. C. Origens e ramificações das artérias mesentéricas cranial e caudal em fetos de caprinos da raça Saanen (Capra hircus 3/4 Linnaeus, 1758). Brazilian Journal of Veterinary Research and Animal Science, São paulo, v. 38, n. 2, p. 69-73, 2001.

GETTY, R. Sisson/Grossman Anatomia dos animais domésticos. Vol. 1-2. 5 ed. Rio de Janeiro: Guanabara Koogan, 1986. 2000 p.

GONÇALEZ, P. O.; SILVA, F. O. C.; SEVERINO, R. S.; DRUMMOND, S. S. Origens e ramificações da artéria celíaca em fetos de suínos (Sus scrofa domesticus - Linnaeus, 1758) da linhagem "rezende". Bioscience Journal, Uberlândia, v. 19, n. 1, p. 87-95, 2003.

HIRANO, L. Q. L.; SANTOS, A. L. Q.; PEREIRA, P. C.; SILVA, J. M. M.; KAMINISHI, A. P. S.; FERREIRA, C. G. Anatomia vascular das artérias renais e gonadais de Podocnemis unifilis Schweigger, 1812 (Testudines, Pelomedusidae). Acta Scientiarum. Biological Sciences, Maringá, v. 31, n. 2, p. 191-194, 2009.
INTERNATIONAL COMMITTEE ON VETERINARY GROSS ANATOMICAL NOMENCLATURE. Nomina anatômica veterinária. 5. ed. Knoxville: World Association on Veterinary Anatomist, 2012. 160 p.

LANGENFELD, M.; PASTEA, E. Anatomical variants of the celiac artery in the sheep, with special reference to the celiomesenteric arterial trunk. Anatomischer Anzeiger, Jena, v. 142, p.168-174, 1977.

MACHADO, G. V.; ROMAGNOLLI, P.; SOUZA, J. R.; TURQUETI, V. S.; ULIANA, S. M.; SILVA, M. H. Suprimento arterial para as glândulas adrenais no ratão-do-banhado (Myocastor coypus Molina, 1782). Archives of Veterinary Science, Curitiba, v. 7, n. 2, p. 9-14, 2002a.

MACHADO, G. V.; SOUZA, J. R.; GONÇALVES, P. R.; PARAZZI, A.; DONIN, D. G. A artéria celíaca e seus ramos no ratão-do banhado (Myocastor coypus - Rodentia: Mammalia). Biotemas, Florianópolis, v. 2, p. 41-54, 2002 b.

MACHADO, M. R. F.; MIGLINO, M. A.; CABRAL, V. P.; ARAÚJO, N. Origem das artérias celíaca e mesentérica cranial em bubalinos (Bubalus bubalis, L. 1758). Brazilian Journal of Veterinary Research and Animal Science, São Paulo, v. 37, n. 22, p. 99-104, 2000.

McNAB, B. Energetics, population, biology and distribution of xenarthrans. In: MONTGOMERY, G. G. (Ed.). The evolution and ecology of armadillos, sloths and vermilinguas. Washington: Smithsonian Institution Press, 1985. p. 219-232.

COLLEAUX, L. Genetic basis of mental retardation. In: JONES, B. C.; MORMÈDE, P. (Ed.). Neurobehavioral Genetics - Methods and applications. 2 ed. New York: CRC Press, 1999. p. 275-290.

NEVES, W. C.; CAVALCANTE FILHO, M. F.; CARVALHO, M. A. M.; ARRIVABENE, M.; MENEZES, D. J. A. Irrigação das glândulas adrenais em cutia dourada (Dasyprocta aguti, rodentia). Revista da FZVA, Uruguaiana, v. 14, n. 2, p. 165-174, 2007.

NICKEL, R.; SCHUMMER, A.; SEIFERLE, E. The anatomy of the domestic animals. Berlin: Verlag Paul Parey, 1981. 440 p.

PEDUTI NETO, J.; BORELLI, V. Origem das artérias celíaca e mesentérica cranial, por tronco comum, em Felis catus domestica. Revista da Faculdade de Medicina Veteterinária, São Paulo, v. 8, p. 395-398, 1970.

REIS, N. R.; PERACCHI, A. L.; PEDRO, W. A.; LIMA. I. Mamíferos do Brasil. Londrina: SEMA/SETI/UEL/UNIFIL/ PPG Ciências Biológicas UEL/EDIFURB/Schering-Plough, 2006. 439 p.

SCHMIDT, D. P.; SCHOENAU, L. S. F. Origem das artérias celíaca e mesentérica cranial por tronco comum em cão. Ciência Rural, Santa Maria, v. 37, n. 2, p. 408-411, 2007.

SILVA, F. O. C.; SEVERINO, R. S.; SANTOS, A. L. Q.; DRUMMOND, S. S.; LIMA, E. M. M.; BRITO, L. F. C.; GARGALHONE, A. G. Irrigação das glândulas adrenais em suínos da raça landrace. Bioscience Journal, Uberlândia, v. 17, n. 1, p. 25-35, 2001.

SOUZA, A. L. R.; REZENDE, L. C.; MORTOZA, A. R.; FERREIRA, J. R. Modelo de suprimento sanguíneo do intestino grosso do tamanduá bandeira (Myrmecophaga tridactyla). Ciência Rural, Santa Maria, v. 40, n. 3, p. 541-547, 2010. 